\title{
Vicarious self-control use and persuadability: The role of resistance effort
}

\author{
Joshua M. Ackerman, University of Michigan \\ joshack@,umich.edu
}

Vicarious processing studies show that people sometimes experience the consequences of others' actions. In the domain of self-regulation, this may result in increased susceptibility to persuasion attempts following mental simulation of another person's self-control use - a vicarious depletion effect. Yet, little is known about the boundaries of such effects. Here, the interactive roles of persuasion content (argument strength) and resistance effort (message favorability) were examined. Vicariously depleted participants expressed greater positivity only toward advocated policies that were initially favorable and used strong arguments, but not toward policies that were initially unfavorable. These findings indicate that people are able to overcome the effects of vicarious depletion when they are highly resistant to the content of persuasive messages.

Keywords: self-control; vicarious; persuasion; influence; self-regulation; attitudes

\section{Introduction}

Humans are naturally social creatures. This sociality provides a number of clear costs and benefits, from division of labor to easier access to friends and romantic partners to the necessity of guarding against interpersonal deception. A less obvious, but potentially powerful, implication of sociality involves the production of vicarious experiences. Such experiences violate the common phenomenology of individuals as unique causal agents. Instead of affective and cognitive states resulting from one's own circumstances, vicarious processing can lead people to experience the affective and cognitive states of others, as in the case of empathy. Vicarious effects arise from the connection between two psychological processes - mental simulation and perspective-taking. Mental simulation is an "as-if" process. It occurs when we imagine or perceive actions, perhaps while waxing nostalgic about the past or fantasizing about the future, thereby evoking mental representations of those actions along with their associated sensorimotor responses (Gallese, Keysers, \& Rizzolatti, 2004; Markman, Klein, \& Suhr, 2009; Mitchell, Banaji, \& Macrae, 2005; Niedenthal, 2007). Perspectivetaking involves the putting of oneself into the shoes of another (Goldstein, Vezich, \& Shapiro, 2014; Todd \& Galinksy, 2014), inducing simulation through the retrieval of similar, selfrelevant past experiences (Gallese et al., 2004; Ruby \& Decety, 2001; Saxe, 2009). Together, these processes allow a perceiver to experience (a perhaps imperfect version of) what a target experiences.

One extremely interesting feature of vicarious processing is that people may experience the sensory and conceptual consequences of states shared with others. This processing can produce feelings of pain (Jackson et al., 2006), dishonesty (Gino \& Galinsky, 2012), cognitive dissonance and guilt reduction (Cooper \& Hogg, 2007; Norton, Monin, Cooper, \& Hogg, 2003; Xu, Bègue, \& Bushman, 
2014), and reward (Hackel, Zaki, \& Van Bavel, 2017), as well as change performance on aptitude tests (Galinsky, Wang, \& Ku, 2008), satiate goals (Tobin, Greenaway, McCulloch, \& Crittall, 2015), and shift the target of self-directed biases from the actor to the perspective-taker (Goldstein \& Cialdini, 2007). Research has also extended this idea to the consequences of selfregulation, showing that people can become cognitively "depleted" and "restored" following vicarious self-control activities (Ackerman, Goldstein, Shapiro, \& Bargh, 2009; Egan, Hirt, \& Karpen, 2012). For instance, participants who simulated another person's struggle to resist tempting food (an activity commonly used in depletion research; Baumeister, Bratslavsky, Muraven, \& Tice, 1998) exhibited less restraint over the price they were willing to pay for consumer products, and they exerted less sustained effort in a lexical generation task (Ackerman et al., 2009). In another example, participants who had previously controlled their thoughts (a depleting endeavor; Wegner, Schneider, Carter, \& White, 1987) persisted longer at an impossible task after taking the perspective of a person who took a nap (Egan et al., 2012).

A recent investigation examined vicarious self-control use in the context of persuasion resistance. Saying "no" to persuasion attempts commonly involves a degree of mental effort such that engaging in prior tasks which involve selfcontrol can subsequently lead people to become more agreeable and compliant (e.g., Burkley, 2008; Petrocelli, Williams, \& Clarkson, 2015; Fennis, Janssen, \& Vohs, 2009; Wheeler, Briñol, \& Hermann, 2007). In several studies of vicarious experience, participants who felt a strong degree of mental connection with another self-control user later expressed more positive attitudes toward the target of persuasive messages (Ackerman, 2018). As an example, taking the perspective of someone resisting tempting food resulted in participants becoming more positive to brands that appeared in an advertisement and to policies advocated for in essays.

Vicarious processing research can help to advance our understanding of specific constructs and to inform the extent to which the social environment influences perceivers. For instance, from the perspective of vicarious self-regulation, this work shows that mere simulations of selfcontrol use can produce the same type of outcomes typically found in the resource depletion literature (Baumeister et al., 1998; Vohs \& Faber, 2007), perhaps suggesting that no physiological "resource" need be depleted (see also Kurzban, 2009; Inzlicht \& Schmeichel, 2012; Job, Dweck, \& Walton, 2010; Molden et al., 2012). Further, the fact that the content of the actions being simulated by perceivers (e.g., resisting food) is disconnected from the content of the perceiver outcomes (e.g., brand and policy attitudes) suggests that the scope of influence from vicarious depletion is potentially quite broad.

Despite the promise of this work, relatively little is known about boundaries of vicarious effects in domains such as self-regulation. Do vicariously depleted people always suffer from impaired use of self-control? Consider, in the context of managing persuasion attempts, where depleted self-control is associated with increased susceptibility (Burkley, Anderson, \& Curtis, 2011), vicarious depletion would potentially leave the targets of persuasion vulnerable to influence from an array of sources, from politicians to advertisers to journalists, regardless of that target's prior opinions and preferences. Opposing a strong message may simply be too difficult following this vicarious experience. Conversely, it may be that prior opinions and preferences inform how people will respond to such persuasion attempts. If depletion primarily involves an unwillingness to resist rather than an inability to resist, consistent with recent perspectives which stress conservation of energy and motivational shifts (e.g., Inzlicht \& Schmeichel, 2012; Muraven et al., 2006; 
Muraven \& Slessareva, 2003), then a vicariously depleted person may be willing to marshal the effort to resist messages that strongly contradict prior attitudes. If so, an unfavorable request (i.e., one promoting an undesired outcome) is likely to produce a relatively high level of resistance effort, whereas a favorable request (i.e., one promoting a desired outcome) is likely to produce a relatively low level of resistance effort. Prior research on individual self-control and persuasion susceptibility has not, as far as I am aware, directly manipulated the role of resistance effort. An understanding of how resistance effort interacts with the content of persuasion attempts to influence message recipients would help to illuminate the process by which vicariously depleted individuals are swayed.

The current study varied both resistance effort and persuasion content in the context of messages about new school policies. After taking the perspective of a person using self-control for an unrelated reason, student participants read an advocacy statement for either a favorable policy (low resistance effort) or an unfavorable policy (high resistance effort). Persuasion content was characterized by use of either weak (low persuasion effort) or strong (high persuasion effort) arguments in the statements, a common technique for identifying the degree of processing allocated to persuasion tasks (Chaiken, 1980; Petty \& Cacioppo, 1986). This procedure also allows for a confirmatory test of prior work on depletion and degree of processing (Ackerman, 2018; Burkley, 2008; Clarkson, Hirt, Jia, \& Alexander, 2010; Wheeler, Briñol, \& Hermann, 2007). Finally, this study incorporated a variety of cognitive and affective measures of mental connection between participant and self-control user (e.g., empathy, oneness) in order to test potential mediators of the effect of vicarious depletion on persuasion and compliance.

\section{Method}

\section{Participants and Design}

Four hundred sixty undergraduates (239 female; mean age $=18.75$ ) completed the full study in exchange for course credit. The study used a 2 (Self-Control Cue: present, absent) X 2 (Persuasion Effort: low/weak arguments, high/strong arguments) X 2 (Resistance Effort: low/favorable policy, high/unfavorable policy) between-participants design. A power analysis was conducted to help determine total sample size (see Supplementary Material section). Study data can be accessed at https: / / osf.io/yx4gf/. The study was approved by the University IRB and all participants provided consent prior to participation.

\section{Procedure}

Upon arrival to the lab, participants were told they would be taking part in two unrelated studies. The first component assessed how people understand the thoughts and feelings of others. Participants watched one of two videos, one in which the actor ate a radish (self-control present) and one in which the actor ate a chocolate-chip cookie (self-control absent). Before watching, all participants were given perspective-taking instructions: "While watching the video please try to take the perspective of the person in the video. Strongly imagine what they might be feeling, thinking and going through." This text was taken from prior vicarious depletion work (e.g., Ackerman et al., 2009) and was intended to encourage participants to mentally simulate the experience of the actor (all participants received this instruction in order to reduce the overall number of experimental variables).

Following this video, participants completed the Brief Mood Introspection Scale (BMIS; Mayer \& Gaschke, 1988), a commonly used mood measure in depletion research that contains subscales for valence and arousal (e.g., Schmeichel \& Vohs, 2009; Vohs \& Faber, 2007). They also answered questions regarding their 
interpretation of the actor's experience (e.g., How difficult was it for the person to eat the food?, How much did the person like the food?, How much self-control do you think it took for the person to eat the food?) and questions regarding their own experience (How difficult was it to watch the person in the video?, How much did you like the person in the video?, How tired/worn out did you feel while watching the person in the video?) on 7-point Likert-type scales. A single-item check used a 9-point scale to measure perspective-taking with the actor (How much did you put yourself in the shoes of the person in the video?). Additionally, a series of items assessed empathic concern (concern, warm, empathy, compassion, softhearted; Oswald, 1996) and oneness/self-other overlap (overlapping circles item; Maner et al., 2002) with the actor. Finally, several other items targeted food-related processes (see Supplementary Material).

In the purported second study, participants were informed that the university Office of Academic Affairs was gathering feedback on several proposed new policies. Participants read an essay that advocated for one of two policies, introduction of either comprehensive senior exams or senior reflection weeks (see Appendices for text). The comprehensive exam essay ("a test of what the student had learned after completing their major, and a certain score would be required if the student was to graduate") was expected to be relatively unfavorable to the student sample (see Wheeler et al., 2007), whereas the reflection week essay ("a class-free, self-directed period used for students to review what they had learned during their college experience, and also to provide extra time for job searches") was expected to be relatively favorable. This expectation was confirmed by a pre-test (see section 2.2.1), suggesting that the effort necessary to resist a message advocating for these policies was higher for the exam policy.

Two versions of each essay were prepared using either weak or strong arguments taken directly from the appendix of Petty and Cacioppo (1986b) for the exam policy and adapted by the author for the reflection week policy. Participants then rated their attitudes about the policy using a five-item semantic differential measure (bad/good, unfavorable/favorable, negative/positive, against/in favor, and harmful/beneficial) with responses made on an 11-point scale (e.g., $-5=$ extremely bad, $0=$ neutral, 5 = extremely good) (see Burkley, 2008). Two measures of perceived message potency (clarity of message, persuasiveness of message) were then given using 7-point scales. Finally, to evaluate compliance, participants answered "If the University asked you to support the proposed policy, would you support it?" (yes/no response).

The measures ended with two free-response manipulation checks (what the person in the video was eating; what the essay was about) followed by two individual difference measures (perspective-taking, self-control), which were collected for exploratory reasons (see Supplementary Material for details), as well as demographics. Lastly, participants were surveyed for suspicion and debriefed.

\section{Essay pretest}

In the main study, participants read an essay that advocated for one of two policies, introduction of either comprehensive senior exams or senior "reflection weeks." The comprehensive exam essay was expected to be relatively unfavorable whereas the reflection week essay was expected to be relatively favorable to the student sample. A pre-test with 115 student participants ( 51 female) from the same university campus evaluated the two essays. Students judged the reflection week policy ( $M=$ 2.03, $S D=1.74$ ) to be more favorable than the comprehensive exam policy $(M=-.07, S D=$ 2.27), $F(1,113)=31.23, p<.001, \eta_{\mathrm{p}}=.22$. Over twice as many people reported being willing to actively support the reflection week $(86.2 \%)$ vs. comprehensive exam policy 
$(34.0 \%), b=2.50$, Wald $=27.22, p<.001, O R$ $=12.15$. These data suggest that the effort necessary to resist an essay advocating for these policies is relatively higher for the exam policy than for the reflection week policy.

\section{Results}

\section{Preliminary analyses}

Twelve participants were removed for expressing relatively accurate suspicion, manipulation check failures, experimenter problems, or not following instructions, leaving 448 total participants. In addition to the analyses below, several ancillary tests are reported in the Supplementary Material section.

The video manipulation did not affect reported liking for the actor, $p=.98$, ruling out the possibility that people become more agreeable because they transfer positivity associated with the video actor to the policy essay. Items assessing perceptions of the actor's experience were combined into a perceived difficulty composite (food liking was reverse-coded; $\alpha=$ $.94)$, and analyzed by ANOVA. A significant effect supported the self-control manipulation, showing that participants judged the actor who ate a radish $(M=6.07, S D=.70)$ to have a more difficult experience than the actor who ate the cookie $(M=1.89, S D=.85), F(1,446)=$ $3221.48, p<.001, \eta_{\mathrm{p}}=.88$. Items assessing participants' own experience watching the video did not show suitable reliability as a composite, and thus these were analyzed as individual items. Compared to participants viewing the cookie video, participants viewing the radish video reported that it was more difficult to watch (radish: $M=3.49, S D=1.93$; cookie: $M=2.25$,
$S D=1.69), F(1,446)=52.20, p<.001, \eta_{\mathrm{p}}=$ .11 , less enjoyable (radish: $M=2.48, S D=1.59$; cookie: $M=2.83, S D=1.41), F(1,446)=6.05$, $p=.014, \eta_{\mathrm{p}}=.01$, and they felt more tired/worn out watching it (radish: $M=3.44, S D$ $=1.88$; cookie: $M=2.86, S D=1.72), F(1,446)$ $=11.53, p=.001, \eta_{\mathrm{p}}=.03$. The manipulation check on perspective-taking was tested using a one-sample t-test against the scale midpoint, indicating that participants did put themselves into the shoes of the actor, $t(447)=12.68, p<$ .001 , although a main effect of the video condition also showed that this tendency was greater with the radish video $(M=6.46, S D=$ $1.85)$ than with the cookie video $(M=5.84, S D$ $=1.95), F(1,446)=11.73, p=.001, \eta_{\mathrm{p}}=.03$. Controlling for self-reported perspective-taking did not change the reported effects, nor did it mediate the effects of condition on attitudes or policy support, and so it is not discussed further. In sum, the above patterns support the experimental paradigm as a manipulation of selfcontrol and therefore the experience of vicarious depletion.

Finally, analysis of the BMIS scale revealed effects of the video on affect valence, $F(1,446)=$ $54.85, p<.001, \eta_{\mathrm{p}}=.11$, and on affect arousal, $F(1,446)=14.73, p<.001, \eta_{\mathrm{p}}=.03$, with the cookie video producing more positive feelings (cookie: $M=44.72, S D=5.93$; radish: $M=$ 40.41, $S D=6.37$ ) but less arousal (cookie: $M=$ 25.68, $S D=3.36$; radish: $M=26.90, S D=$ $3.35)$ than the radish video. Controlling for these effects did not change any results from the primary analyses, nor did they mediate the primary outcomes, and thus they are not discussed further. 


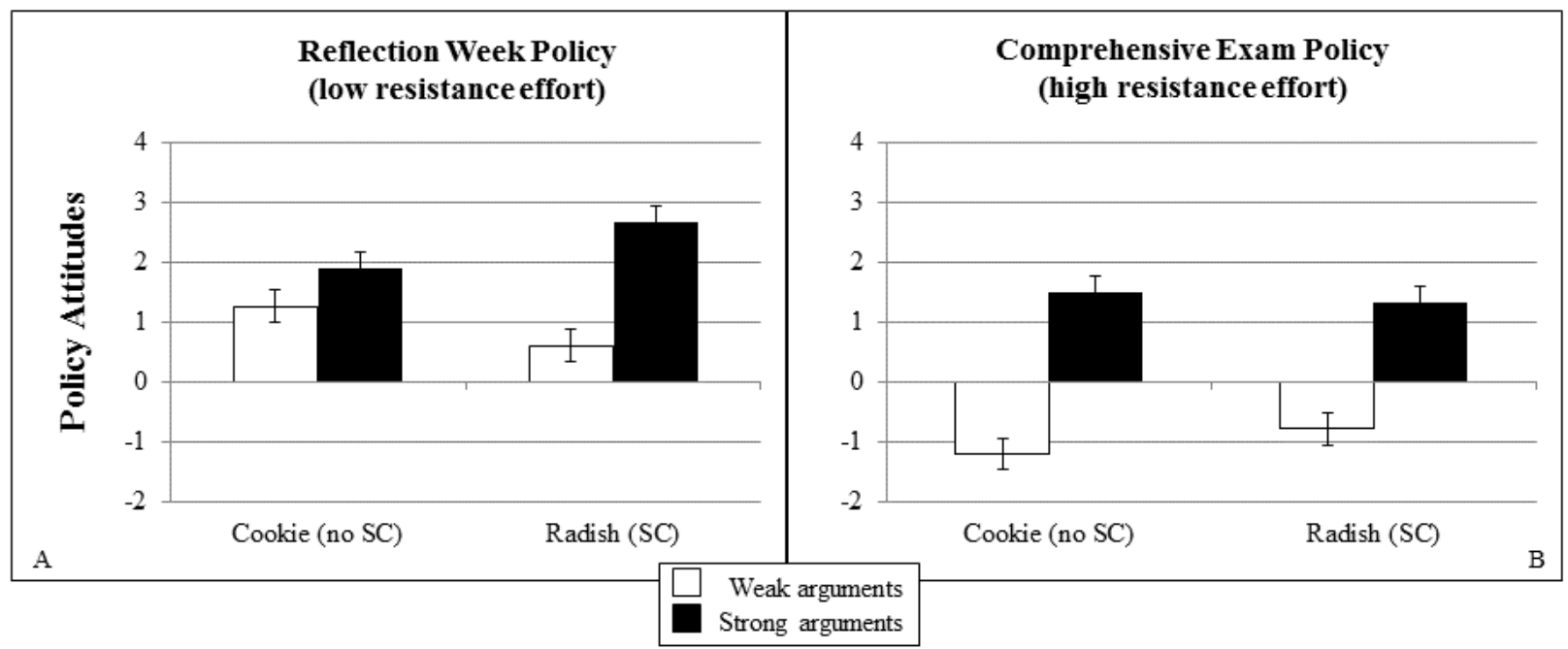

Figure 1. Effects of self-control video, argument strength (persuasion effort), and policy type (resistance effort) on attitudes. Following strong persuasive arguments, vicariously depleted people expressed more positive attitudes towards a relatively favorable policy (Panel A) but not towards a relatively unfavorable policy (Panel B). Error bars represent standard errors.

\section{Attitudes}

A Self-Control Cue X Persuasion Effort X Resistance Effort ANOVA on a composite of the attitude items $(\alpha=.96)$ revealed main effects of Resistance Effort, $F(1,440)=53.15, p<.001$, $\eta_{\mathrm{p}}=.11$, and Persuasion Effort, $F(1,440)=$ 94.48, $p<.001, \eta_{\mathrm{p}}=.18$, as well as a Resistance Effort X Persuasion Effort interaction, $F(1,440)$ $=7.44, p=.007, \eta_{\mathrm{p}}=.02$. However, these were qualified by a significant three-way interaction with Self-Control Cue, $F(1,440)=$ 7.10, $p=.008, \eta_{\mathrm{p}}=.02$. To decompose this interaction, planned contrasts were examined within each type of policy essay.

When reading an essay advocating for the relatively favorable reflection week (Figure 1A), strong arguments led participants who had taken the perspective of a self-control user to exhibit more positive attitudes than participants who had taken the perspective of a person not using selfcontrol, $F(1,440)=4.21, p=.041, \eta_{\mathrm{p}}=.01$. Weak arguments instead produced a marginal effect in the opposite direction, $F(1,440)=$
2.85, $p=.092, \eta_{\mathrm{p}}=.01$. Alternate comparisons within video condition showed that, after watching the radish video (self-control present), policy attitudes were more positive following strong messages than weak messages, $F(1,440)=$ 29.63, $p<.001, \eta_{\mathrm{p}}=.06$. However, this difference was not significant after watching the cookie video (self-control absent), $p=.11$. This pattern of results suggests that, when resistance effort was low (i.e., when the advocated policy is relatively favorable), vicariously depleted people were relatively more persuaded by strong persuasion content.

In comparison, when reading an essay advocating for the unfavorable comprehensive exam (Figure 1B), neither strong $(p=.63)$ nor weak $(p=.27)$ arguments led to a differential effect of the type of video watched. Comparisons within video condition showed that policy attitudes were more positive following strong messages than weak messages both for participants watching the radish video (selfcontrol present), $F(1,440)=29.12, p<.001$, $\eta_{\mathrm{p}}=.06$, and for participants watching the cookie video (self-control absent), $F(1,440)=$ 
50.57, $p<.001, \eta_{\mathrm{p}}=.10$. This pattern of results suggests that people could be persuaded by strong persuasion content, even for a generally unfavorable policy, yet vicarious depletion did not further elevate susceptibility when initial resistance effort was high.

\section{Choice}

The three condition variables and their interactions were entered into a logistic regression analysis on the choice measure. Results appear in Table 1. Main effects emerged for Self-Control Cue, Resistance Effort, and Persuasion Effort, along with two-way interactions of Self-Control Cue X Resistance Effort and Self-Control Cue X Persuasion Effort. All of these effects were qualified by a SelfControl Cue X Persuasion Effort X Resistance Effort interaction which mimicked the results of the attitude analyses. Pairwise comparisons were tested using the generalized linear model in SPSS.

When reading an essay advocating for a relatively favorable reflection week, strong arguments led participants who had taken the perspective of a self-control user to express directionally more policy support (88.89\%) than participants who had taken the perspective of a person not using self-control (81.03\%), though this was not a significant effect, $p=.241$. Weak arguments instead produced less support when participants took the perspective of a self-control user (54.10\%) compared to a person not using self-control $(74.00 \%), p=.025$. Comparisons within video condition showed that, after watching the radish video (self-control present), policy support was greater in response to strong messages than to weak messages, $p<.001$. This effect did not occur after watching the cookie video (self-control absent), $p=.383$. These patterns are generally consistent with those previously found for policy attitudes.

In comparison, when reading an essay advocating for a relatively unfavorable comprehensive exam, strong arguments led participants who had taken the perspective of a self-control user to express even less policy support (44.64\%) than participants who had taken the perspective of a person not using selfcontrol $(70.91 \%), p=.004$. Weak arguments did not produce the same effect, $p=.612$. Comparisons within video condition showed that the radish video led to greater support in response to strong $(44.64 \%)$ than to weak (20.37\%) arguments, $p=.005$, and this difference was exaggerated after watching the cookie video (70.91\% vs.

$16.67 \%$, respectively), $p<.001$. Unlike responses to the favorable reflection week policy, the effect of strong arguments on exam policy support was relatively greater for non-vicariously depleted people, consistent with the attitude findings. 
Table 1. Logistic regression results for choice of policy support

\begin{tabular}{|c|c|c|c|c|c|}
\hline Variable & $B$ & S.E. & Wald & $p$ & $\operatorname{Exp}(B)$ \\
\hline Self-control Cue & 1.106 & .400 & 7.627 & .006 & 3.023 \\
\hline Resistance Effort & 2.295 & .510 & 20.269 & .000 & 9.920 \\
\hline Persuasion Effort & -1.148 & .432 & 7.072 & .008 & .317 \\
\hline Self-control Cue $*$ Resistance Effort & -1.733 & .678 & 6.530 & .011 & .177 \\
\hline Self-control Cue $*$ Persuasion Effort & -1.352 & .628 & 4.634 & .031 & .259 \\
\hline Resistance Effort * Persuasion Effort & -.767 & .663 & 1.337 & .248 & .464 \\
\hline $\begin{array}{l}\text { Self-control Cue * Resistance Effort * Persuasion } \\
\text { Effort }\end{array}$ & 2.861 & .930 & 9.472 & .002 & 17.480 \\
\hline
\end{tabular}

\section{General Discussion}

Given the fundamentally social nature of our species, and the extent to which we readily identify with close others, vicarious processing is likely a regular feature of the human experience. Research demonstrating that perceivers can exhibit the consequences of vicariously processed activities, from pain to reward to self-control depletion, speaks to the wide-ranging impact of this aspect of sociality. Yet, relatively little is known about the boundaries of such effects. The current study examined contexts under which vicarious depletion affects persuasion resistance. That is, to what extent do message factors (persuasion effort) and target factors (resistance effort) influence perceivers?

Here, when resistance effort was low, strong arguments led to more agreement and compliance after taking the perspective of a self-control user. This result replicates prior findings showing vicarious depletion increases persuadability (absent manipulation of resistance effort; Ackerman, 2018). However, when resistance effort was high, attitudes were relatively unaffected by taking the perspective of a self- control user. In fact, strong arguments produced less choice compliance following perspectivetaking. This divergence between levels of resistance effort may indicate that conditions likely to elicit vicarious depletion produce an increased tendency to pursue dominant impulses, resulting in more positivity to favorable requests and somewhat more negativity to unfavorable requests. This pattern is also consistent with the interpretation that vicariously depleted people will counter-argue against persuasion attempts when strongly motivated, consistent with a motivational model of self-control (Inzlicht \& Schmeichel, 2012; Muraven et al., 2006; Muraven \& Slessareva, 2003). The fact that this result did not emerge following exposure to weak arguments suggests that these persuasion cues are easily disregarded even when people are vicariously depleted, consistent with certain findings in the non-vicarious depletion literature (Burkley, 2008; Clarkson et al., 2010; Petrocelli et al., 2015).

Interestingly, the extent of felt connection between perceiver and self-control user did not drive the attitude and choice effects (see Supplementary Material). It may be that the 
initial perspective-taking instruction that all participants received interfered with natural (undirected) tendencies toward social connection, or it may be that mental simulation of others' activities does not necessarily rely on the phenomenological experience of connection. Nevertheless, these data support the connection between vicarious self-control use and heightened agreeableness but also indicate that this connection depends on the initial favorability of advocated positions to persuasion targets. Thus, this study makes two key contributions: (1) it replicates the effect of vicarious depletion on persuasion susceptibility using a large sample size, and (2) it demonstrates that this effect is limited to persuasion attempts featuring strong arguments and low levels of resistance to the message.

\section{Theoretical Implications and Future Directions}

The current findings contribute to our understanding of how self-regulatory processes function in the domain of persuasion susceptibility and resistance, and to the broader issue of how vicarious experiences impact attitude and behavior change. This work also grows the theoretical foundations of the vicarious depletion effect by testing the processing channels affected by this form of depletion (i.e., centrally-processed forms of persuasion appear to play the primary role) and the conditions under which persuasion is likely to produce compliance (i.e., recipients do not increase compliance with messages advocating for very unfavorable policies). One prior investigation found that nonvicarious depletion had greater impact on persuasion targets when those targets were highly certain about their initial attitudes (Petrocelli et al., 2015). Certainty is usually associated with greater resistance to change (e.g., Rucker, Tormala, Petty, \& Briñol, 2013), suggesting a divergence in the implications of depletion for attitudes depending on the source of that depletion (vicarious or non-vicarious). Future research is therefore important for disentangling the processes and outcomes that are shared, and those which are not shared, between vicarious and non-vicarious self-control use.

The literature also would benefit from expanding investigation into the contexts associated with, and impacted by, vicarious selfcontrol loss. For instance, vicarious depletion may be most likely to emerge when people can easily observe the impulse struggles of others, as might occur during social shopping trips, communal meals, and support group meetings. Occupational settings also often include a substantial degree of communication regarding self-control exertion. Vicarious processing in these settings could culminate in problems such as burnout, decision-making errors, and dishonesty (Danziger, Levav, \& Avnaim-Pesso, 2011; Gino, Schweitzer, Mead, \& Ariely, 2011; Linder et al., 2014). Even beyond professional environments, these processes could impact the types of information into which people place confidence (Lazer et al., 2018). An understanding of the boundaries of vicarious effects additionally may help illuminate practical factors useful for improving self-control outcomes in socially-relevant contexts. For example, cues that promote psychological distance from self-control users may eliminate or reverse the outcomes of vicarious depletion.

Just as importantly, this work may offer insights into the current state of self-control depletion research. This literature has faced recent criticism in the face of inconsistent findings between individual studies, metaanalyses, and large-scale replication attempts (e.g., Carter, Kofler, Forster, \& McCullough, 2015; Hagger, Wood, Stiff, \& Chatzisarantis, 2010; Hagger et al., 2016). Other researchers have questioned the general concept of depletion as a loss of some internal self-regulatory resource, as formulated by the strength model of self-control (Kurzban, 2009; Lurquin \& Miyake, 2017; Molden et al., 2012). A number of alternate interpretations have been put forth for 
depletion-like effects, including opportunity cost calculations (Kurzban, Duckworth, Kable, \& Myers, 2013), goal reprioritization (Inzlicht, Schmeichel, \& Macrae, 2014), and other motivational accounts (Molden, Hui, \& Scholer, 2017). Vicarious approaches to depletion may be an additional means of addressing these issues. An internal resource model would not appear to fit the findings of such studies because perceivers do not engage in self-control activities themselves. The lack of increased support for the highresistance policy in the current study also is inconsistent with this type of model. Vicarious effects such as those found here instead may be better interpreted as resulting from motivational shifts (e.g., wanting to focus on the positive after simulating a negative experience) or mental fatigue (whether real or perceived; Clarkson, Otto, Hassey, Hirt, 2016; Molden et al., 2017). Clearly, however, future study of vicarious depletion is needed to explore the psychological processes that contribute to shifts in attitudes and decisions, even ones that are irrelevant to the content of the original actor's behavior.

In sum, the present research demonstrates ways in which responses to persuasion attempts depend not only on one's own actions, but on the actions of others. This work expands our understanding of how self-control use functions in interpersonal environments, but also contributes to the broader literature on vicarious processing. Although, strictly speaking, we experience the world through our own eyes and not those of others, how our brain processes the world is not quite so clear-cut. Awareness of the limits of this connected brain can improve knowledge about its functions but also may aid in developing effective means of managing the world of social influence. 


\section{Acknowledgements}

I thank Yuching Lin for her dedicated work in the implementation of this study and Spencer Dobbs for his assistance in preparing the manuscript.

\section{References}

Ackerman, J. M. (2018). Persuasion by proxy: Effects of vicarious self-control use on reactions to persuasion attempts. Social Cognition, 36(3), 275-300.

Ackerman, J. M., Goldstein, N. J., Shapiro, J. R., \& Bargh, J. A. (2009). You Wear Me Out The Vicarious Depletion of Self-Control. Psychological Science, 20(3), 326-332.

Baumeister, R. F., Bratslavsky, E., Muraven, M., \& Tice, D. M. (1998). Ego depletion: is the active self a limited resource? Journal of Personality and Social Psychology, 74, 12521265.

Burkley, E. (2008). The role of self-control in resistance to persuasion. Personality and Social Psychology Bulletin, 34(3), 419-431.

Burkley, E., Anderson, D., \& Curtis, J. (2011). You Wore Me Down: Self-Control Strength and Social Influence. Social and Personality Psychology Compass, 5(7), 487-499.

Carter, E. C., Kofler, L. M., Forster, D. E., \& McCullough, M. E. (2015). A series of meta-analytic tests of the depletion effect: Self-control does not seem to rely on a limited resource. Journal of Experimental Psychology: General, 144(4), 796-815.

Chaiken, S. (1980). Heuristic versus systematic information processing and the use of source versus message cues in persuasion. Journal of Personality and Social Psychology, 39(5), 752 766.

Clarkson, J. J., Hirt, E. R., Jia, L., \& Alexander, M. B. (2010). When perception is more than reality: the effects of perceived versus actual resource depletion on self-regulatory behavior. Journal of Personality and Social Psychology, 98(1), 29-46.

Clarkson, J. J., Otto, A. S., Hassey, R., \& Hirt, E. R. (2016). Perceived mental fatigue and selfcontrol. In E. R. Hirt, J. J. Clarkson, and L.
Jia (Eds.), Self-Regulation and Ego Control (pp. 185-202). Amsterdam: Elsevier.

Cooper, J., \& Hogg, M. A. (2007). Feeling the anguish of others: A theory of vicarious dissonance. Advances in Experimental Social Psychology, 39, 359-403.

Danziger, S., Levav, J., \& Avnaim-Pesso, L. (2011). Extraneous factors in judicial decisions. Proceedings of the National Academy of Sciences, 108(17), 6889-6892.

Egan, P. M., Hirt, E. R., \& Karpen, S. C. (2012). Taking a fresh perspective: Vicarious restoration as a means of recovering selfcontrol. Journal of Experimental Social Psychology, 48(2), 457-465.

Fennis, B. M., Janssen, L., \& Vohs, K. D. (2009). Acts of Benevolence: A Limited-Resource Account of Compliance with Charitable Requests. Journal of Consumer Research, 35(6), 906-924.

Galinsky, A. D., Wang, C. S., \& Ku, G. (2008). Perspective-takers behave more stereotypically. Journal of Personality and Social Psychology, 95 (2), 404-419.

Gallese, V., Keysers, C., \& Rizzolatti, G. (2004). A unifying view of the basis of social cognition. Trends in cognitive sciences, 8(9), 396-403.

Gino, F., Schweitzer, M. E., Mead, N. L., \& Ariely, D. (2011). Unable to resist temptation: How self-control depletion promotes unethical behavior. Organizational Behavior and Human Decision Processes, 115(2), 191-203.

Goldstein, N. J., \& Cialdini, R. B. (2007). The spyglass self: a model of vicarious selfperception. Journal of Personality and Social Psychology, 92 (3), 402-417.

Goldstein, N. J., Vezich, I. S., \& Shapiro, J. R. (2014). Perceived perspective taking: When others walk in our shoes. Journal of Personality and Social Psychology, 106(6), 941-960.

Gunia, B. C., Sivanathan, N., \& Galinsky, A. D. (2009). Vicarious entrapment: Your sunk costs, my escalation of commitment. Journal of Experimental Social Psychology, 45(6), 12381244.

Hackel, L. M., Zaki, J., \& Van Bavel, J. J. (2017). Social identity shapes social valuation: evidence from prosocial behavior and vicarious reward. Social cognitive and affective neuroscience, 12(8), 1219-1228. 
Hagger, M. S., Chatzisarantis, N. L., Alberts, H., Anggono, C. O., Batailler, C., Birt, A. R., ... \& Calvillo, D. P. (2016). A multilab preregistered replication of the egodepletion effect. Perspectives on Psychological Science, 11(4), 546-573.

Hagger, M. S., Wood, C., Stiff, C., \& Chatzisarantis, N. L. (2010). Ego depletion and the strength model of self-control: A meta-analysis. Psychological Bulletin, 136(4), 495-525.

Inzlicht, M., \& Schmeichel, B. J. (2012). What is ego depletion? Toward a mechanistic revision of the resource model of self-control.

Perspectives on Psychological Science, 7(5), 450463.

Inzlicht, M., Schmeichel, B. J., \& Macrae, C. N. (2014). Why self-control seems (but may not be) limited. Trends in Cognitive Sciences, 18(3), 127-133.

Jackson, P. L., Brunet, E., Meltzoff, A. N., \& Decety, J. (2006). Empathy examined through the neural mechanisms involved in imagining how I feel versus how you feel pain. Neuropsychologia, 44(5), 752-761.

Job, V., Dweck, C. S., \& Walton, G. M. (2010). Ego depletion-Is it all in your head? Implicit theories about willpower affect selfregulation. Psychological Science, 21, 16861693.

Kurzban, R. (2009). Does the brain consume additional glucose during self-control tasks? Evolutionary psychology: An international journal of evolutionary approaches to psychology and behavior, 8(2), 244-259.

Kurzban, R., Duckworth, A., Kable, J. W., \& Myers, J. (2013). An opportunity cost model of subjective effort and task performance. Behavioral and Brain Sciences, 36(06), 661 679.

Lazer, D. M., Baum, M. A., Benkler, Y., Berinsky, A. J., Greenhill, K. M., Menczer, F., et al. (2018). The science of fake news. Science, 359(6380), 1094-1096.

Linder, J. A., Doctor, J. N., Friedberg, M. W., Nieva, H. R., Birks, C., Meeker, D., \& Fox, C. R. (2014). Time of Day and the Decision to Prescribe Antibiotics. JAMA Internal Medicine. Published online October 06, 2014. Retrieved from: http: //archinte.jamanetwork.com/article.as px?articleid $=1910546$

Lurquin, J. H., \& Miyake, A. (2017). Challenges to ego-depletion research go beyond the replication crisis: A need for tackling the conceptual crisis. Frontiers in Psychology, 8, 568.

Maner, J. K., Luce, C. L., Neuberg, S. L., Cialdini, R. B., Brown, S., \& Sagarin, B. J. (2002). The effects of perspective taking on motivations for helping: Still no evidence for altruism. Personality and Social Psychology Bulletin, 28(11), 1601-1610.

Markman, K. D., Klein, W. M., \& Suhr, J. A. (Eds.). (2009). Handbook of imagination and mental simulation. New York: Psychology Press.

Mayer, J. D., \& Gaschke, Y. N. (1988). The experience and meta-experience of mood. Journal of Personality and Social Psychology, 55, 102-111.

Mitchell, J. P., Banaji, M. R., \& MacRae, C. N. (2005). The link between social cognition and self-referential thought in the medial prefrontal cortex. Journal of cognitive neuroscience, 17(8), 1306-1315.

Molden, D. C., Hui, C. M., \& Scholer, A. A. (2017). What limits self-control? A motivated effortallocation account. In D. de Ridder, M. Adriaanse, and K. Fujita (Eds.), The Routledge International Handbook of Self-Control in Health and Wellbeing (pp. 129-142). London, UK: Routledge.

Molden, D. C., Hui, C. M., Scholer, A. A., Meier, B. P., Noreen, E. E., D’Agostino, P. R., \& Martin, V. (2012). Motivational versus metabolic effects of carbohydrates on selfcontrol. Psychological Science, 23(10), 1137 1144.

Muraven, M., Shmueli, D., \& Burkley, E. (2006). Conserving self-control strength. Journal of Personality and Social Psychology, 91, 524-537.

Muraven, M., \& Slessareva, E. (2003). Mechanisms of self-control failure: Motivation and limited resources. Personality and Social Psychology Bulletin, 29(7), 894-906.

Niedenthal, P. M. (2007). Embodying emotion. Science, 316(5827), 1002-1005.

Norton, M. I., Monin, B., Cooper, J., \& Hogg, M. A. (2003). Vicarious dissonance: Attitude change from the inconsistency of others. 
Journal of Personality and Social Psychology, 85, 47-62.

Oswald, P. A. (1996). The effects of cognitive and affective perspective taking on empathic concern and altruistic helping. The Journal of Social Psychology, 136(5), 613-623.

Petrocelli, J. V., Williams, S. A., \& Clarkson, J. J. (2015). The bigger they come, the harder they fall: The paradoxical effect of regulatory depletion on attitude change. Journal of Experimental Social Psychology, 58, 82-94.

Petty, R. E., \& Cacioppo, J. T. (1986a). The elaboration likelihood model of persuasion. Advances in Experimental Social Psychology, 19, 123-205.

Petty, R. E., \& Cacioppo, J. T. (1986b). Methodological Factors in the ELM. In Communication and Persuasion (pp. 25-59). New York: Springer.

Ruby, P., \& Decety, J. (2001). Effect of subjective perspective taking during simulation of action: a PET investigation of agency. Nature Neuroscience, 4(5), 546-550.

Rucker, D. D., Tormala, Z. L., Petty, R. E., \& Briñol, P. (2014). Consumer conviction and commitment: An appraisal-based framework for attitude certainty. Journal of Consumer Psychology, 24(1), 119-136.

Saxe, R. (2009). The happiness of the fish: Evidence for a common theory of one's own and others' actions. In Keith Markman, Bill Klein and Julie Suhr (Eds.), The Handbook of Imagination and Mental Simulation (pp. 257266). New York: Psychology Press.

Schmeichel, B. J., \& Vohs, K. (2009). Self-affirmation and self-control: affirming core values counteracts ego depletion. Journal of Personality and Social Psychology, 96, 770-782.

Tobin, S. J., Greenaway, K. H., McCulloch, K. C., \& Crittall, M. E. (2015). The role of motivation for rewards in vicarious goal satiation. Journal of Experimental Social Psychology, 60, 137-143.

Todd, A. R., \& Galinsky, A. D. (2014).

Perspective-taking as a strategy for improving intergroup relations: Evidence, mechanisms, and qualifications. Social and Personality Psychology Compass, 8(7), 374-387.
Vohs, K. D., \& Faber, R. J. (2007). Spent resources: Self-regulatory resource availability affects impulse buying. Journal of Consumer Research, 33(4), 537-547.

Wegner, D. M., Schneider, D. J., Carter, S. R., \& White, T. L. (1987). Paradoxical effects of thought suppression. Journal of Personality and Social Psychology, 53(1), 5-13.

Wheeler, S. C., Briñol, P., \& Hermann, A. D. (2007). Resistance to persuasion as selfregulation: Ego-depletion and its effects on attitude change processes. Journal of Experimental Social Psychology, 43(1), 150156.

Xu, H., Bègue, L., \& Bushman, B. (2014). Washing the guilt away: effects of personal versus vicarious cleansing on guilty feelings and prosocial behavior. Frontiers in human neuroscience, 8, 97-101. 